\title{
Ecologists can enable communities to implement malaria vector control in Africa
}

W Richard Mukabana ${ }^{1}$, Khadija Kannady², G Michael Kiama², Jasper N Ijumba ${ }^{3}$, Evan M Mathenge ${ }^{1}$, Ibrahim Kiche ${ }^{4}$, Gamba Nkwengulila ${ }^{3}$, Leonard Mboera ${ }^{5}$, Deo Mtasiwa ${ }^{2}$, Yoichi Yamagata ${ }^{6}$, Ingeborg van Schayk ${ }^{7}$, Bart GJ Knols ${ }^{8,9}$, Steven W Lindsay ${ }^{10}$, Marcia Caldas de Castro ${ }^{11}$, Hassan Mshinda12, Marcel Tanner ${ }^{13}$, Ulrike Fillinger ${ }^{1,10}$ and Gerry F Killeen*10,12,13

Address: ${ }^{1}$ Department of Zoology, University of Nairobi, Nairobi, Kenya, ${ }^{2}$ City Medical Office of Health, Dar es Salaam City Council, Dar es Salaam, United Republic of Tanzania, ${ }^{3}$ Department of Zoology and Marine Biology, University of Dar es Salaam, Dar es Salaam, United Republic of Tanzania, ${ }^{4}$ Rusinga Island Child and Family Programme/Christian Children's Fund-Kenya, Rusinga Island, Suba District, Kenya, ${ }^{5}$ National Institute for Medical Research, Dar es Salaam, Tanzania, ${ }^{6}$ Japan International Cooperation Agency, Tokyo, Japan, ${ }^{7}$ National Library of Medicine, Washington, DC, USA, ${ }^{8}$ Entomology Unit, FAO/IAEA Agriculture and Biotechnology Laboratory, Seibersdorf, Austria, ${ }^{9}$ Laboratory of Entomology, Wageningen University \& Research Centre, Wageningen, The Netherlands, ${ }^{10}$ School of Biological and Biomedical Sciences, Durham University, Durham, UK, ${ }^{11}$ Department of Geography, University of South Carolina, Columbia, South Carolina, USA, ${ }^{12}$ Ifakara Health Research and Development Centre, Ifakara, United Republic of Tanzania and ${ }^{13}$ Department of Public Health and Epidemiology, Swiss Tropical Institute, Basel, Switzerland

Email: W Richard Mukabana - rmukabana@uonbi.ac.ke; Khadija Kannady - kadkhadija@yahoo.co.uk; G Michael Kiama - gkilleen@ihrdc.or.tz; Jasper N Ijumba - jasperijumba@hotmail.com; Evan M Mathenge - emathenge@mbita.mimcom.net;

Ibrahim Kiche - ikiche@mbita.mimcom.net; Gamba Nkwengulila - gamba@udsm.ac.tz; Leonard Mboera - lmboera@nimr.or.tz;

Deo Mtasiwa - rcmoh@raha.com; Yoichi Yamagata - yamagata_yoichi@hotmail.com; Ingeborg van Schayk - inga@aon.at;

Bart GJ Knols - b.knols@iaea.org; Steven W Lindsay - s.w.lindsay@durham.ac.uk; Marcia Caldas de Castro - mcaldas@sc.edu;

Hassan Mshinda - mshinda_hassan@yahoo.co.uk; Marcel Tanner - marcel.tanner@unibas.ch; Ulrike Fillinger - Ulrike.fillinger@durham.ac.uk; Gerry F Killeen* - gkilleen@ihrdc.or.tz

* Corresponding author

Published: 03 February 2006

Malaria Journal2006, 5:9 doi:10.1186/1475-2875-5-9
Received: 12 November 2005

Accepted: 03 February 2006

This article is available from: http://www.malariajournal.com/content/5/I/9

(c) 2006Mukabana et al; licensee BioMed Central Ltd.

This is an Open Access article distributed under the terms of the Creative Commons Attribution License (http://creativecommons.org/licenses/by/2.0), which permits unrestricted use, distribution, and reproduction in any medium, provided the original work is properly cited.

\begin{abstract}
Background: Integrated vector management (IVM) for malaria control requires ecological skills that are very scarce and rarely applied in Africa today. Partnerships between communities and academic ecologists can address this capacity deficit, modernize the evidence base for such approaches and enable future scale up.

Methods: Community-based IVM programmes were initiated in two contrasting settings. On Rusinga Island, Western Kenya, community outreach to a marginalized rural community was achieved by University of Nairobi through a community-based organization. In Dar es Salaam, Tanzania, Ilala Municipality established an IVM programme at grassroots level, which was subsequently upgraded and expanded into a pilot scale Urban Malaria Control Programme with support from national academic institutes.
\end{abstract}

Results: Both programmes now access relevant expertise, funding and policy makers while the academic partners benefit from direct experience of community-based implementation and 
operational research opportunities. The communities now access up-to-date malaria-related knowledge and skills for translation into local action. Similarly, the academic partners have acquired better understanding of community needs and how to address them.

Conclusion: Until sufficient evidence is provided, community-based IVM remains an operational research activity. Researchers can never directly support every community in Africa so communitybased IVM strategies and tactics will need to be incorporated into undergraduate teaching programmes to generate sufficient numbers of practitioners for national scale programmes. Academic ecologists at African institutions are uniquely positioned to enable the application of practical environmental and entomological skills for malaria control by communities at grassroots level and should be supported to fulfil this neglected role.

\section{Background}

Better intervention technologies for malaria control are all clearly desirable but, taking insecticide-treated nets (ITNs) as an example, it is also clear that their cost-effective delivery remains the dominant obstacle to effective application in Africa [1]. Recent experiences with social marketing [25], public-private partnerships[6], decentralization [7-9] and community participation $[10,11]$ have all provided renewed cause for optimism and shown that even the most isolated African communities can be protected from malaria through sustainable delivery mechanisms. Larval control has the potential to radically reduce malaria transmission in even the most challenging African settings [12$16]$ and is now being reconsidered as a complementary intervention to current priorities such as bednets and access to early diagnosis and prompt treatment $[12,17,18]$. Control of immature aquatic stages of Anopheles mosquitoes may have particular promise in urban settings where large numbers of people can be protected in a relatively small area and rural settings with focal, seasonal breeding sites $[19,20]$. Apart from budgetary constraints, the major obstacles to delivering these interventions to African communities appear to be a major shortfall of capacity in terms of trained personnel at all levels and a paucity of appropriate implementation structures $[12,15,21]$.

Larval control is a labour intensive undertaking. This particularly applies to the major African malaria vectors, such as Anopheles gambiae sibling species, that are best tackled with rigorous searches on foot [14-16,22], because they colonize a large variety of habitats distributed widely over space and time [23-31]. In contrast, Anopheles funestus often requires substantial environmental manipulation or modification because this species prefers large water bodies partly shaded by vegetation that are often inaccessible by foot $[13,14,31]$. Larval control also requires unusual specialist skills, at all levels from community volunteer up to Ph.D. scientist $[14,16,22,32-36]$. As compared with delivery of bed nets or clinical services, traditional mosquito abatement methods are a predominantly outdoors activity best implemented by personnel more concerned with mosquitoes than their endophilic human victims:

The supreme importance of getting into the field and overseeing the work must be impressed on all people in charge of malaria control. Good mosquito control means killing larvae in the field, not proud display of specimen in the office [37]

Indeed, Fred Soper, perhaps the greatest mosquito killer in history, recognized that mosquito abatement requires a basic minimum of ecological understanding and an appetite for hard work in challenging climatic conditions $[22,35]$. Members of the most marginalized communities are adept amateur ecologists and enthusiastic advocates of mosquito abatement once provided with access to relevant knowledge, skills and resources. Communities represent the greatest and least exploited resource available for malaria control in Africa today. Similarly to the large-scale environmental management endeavours that America used to simultaneously rebuild its economy and roll back malaria [38], mosquito abatement may represent an equitable and productive way to utilize donor support and locally-generated funds in Africa. To mobilize this underutilized resource requires the input of skilled personnel at all levels from the grassroots of the community up through districts, regions and national programmes.

Partnerships between academic institutions and communities have proven successful for managing not only mosquitoes and malaria $[10,11,32-34,39,40]$, but also a plethora of different vector-borne diseases [41-46] and environmental hazards [47-50]. Students and scientists from academic departments specializing in ecological, environmental health and engineering disciplines are ideally suited to field-based research in mosquito control and possess many of the skills essential for community-based integrated vector management (IVM). IVM goes beyond simply delivering proven interventions and considers malaria transmission as a property of the local ecosystem which can be managed with judiciously chosen tools [18]. While these interventions are often technologies such as bednets or insecticides, they also include systems inter- 


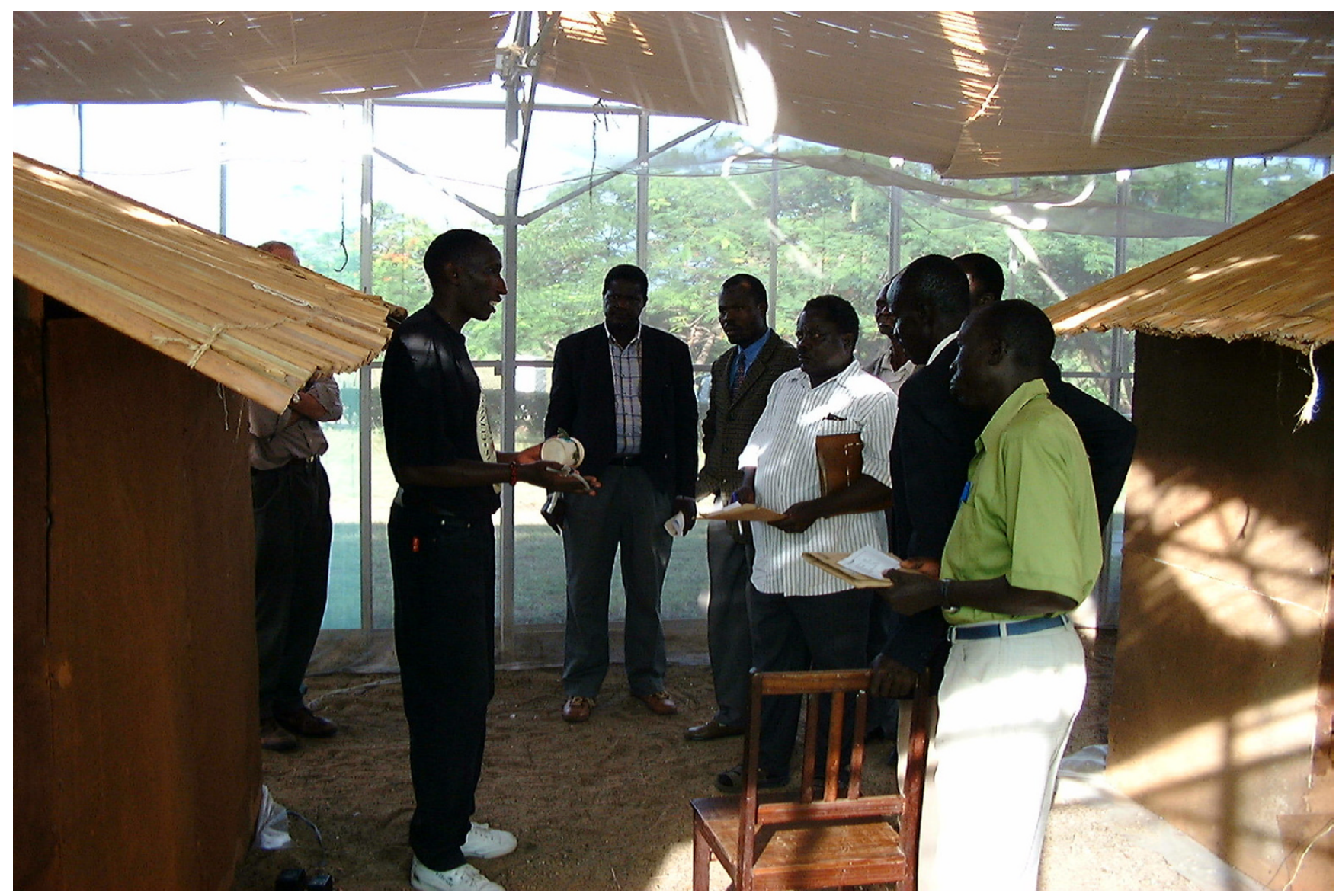

Figure I

One of the authors from the University of Nairobi explains his research to community members and opinion leaders as well as government officials during an open day at the Mbita Point Research and Training Centre of the International Centre of Insect Physiology and Ecology, near Rusinga Island, western Kenya.

ventions that improve the delivery of these technologies by public health programmes or that minimize malaria transmission hazard by improving intersectoral management of the ecosystem. In the increasingly democratic context of modern Africa, systems interventions for public health or ecosystems management cannot be accomplished without the consensus and involvement of the community. The authoritarian approach applied during the colonial era, when IVM was most prominent, is no longer desirable or acceptable. Great progress has been made with horizontal community-based health programmes for delivering technologies such as drugs, diagnostics and bednets. However, with the exception of indoor residual spraying programmes in southern Africa $[51,52]$, vertical programmes to deliver community-level mosquito control interventions have largely failed to adopt community-based approaches. By comparison, wildlife conservation [53], pollution control [50] and veterinary vector control [46] programmes have decades of experience with community-based ecosystems manage- ment and have achieved notable successes in recent years. Integrating ecologists into malaria control should greatly enhance the capacity of national malaria control programmes to deliver community-based IVM programmes. Africa needs large numbers of applied ecologists at all levels if IVM for malaria control is to be effectively and sustainably implemented on national scales. A massive and rapid expansion of this skills base can be achieved by active collaboration of academic ecologists with community-based organizations and local government.

\section{Methods}

Community-based integrated malaria control programmes were initiated in two contrasting settings. First, a sensitization, mobilization and training collaboration was initiated between the Department of Zoology, University of Nairobi, the Rusinga Island Child and Family Programme of the Christian Children's Fund, and a marginalized rural community on Rusinga Island, western Kenya. Collaboration was established at a regular meeting 
of a local health coalition, intended to maximize coordination between local stakeholders. Second, the Ilala Municipal Council in Dar es Salaam, Tanzania established community-based monitoring systems for implementing mosquito control at grassroots level through street health committees. The municipal programme was then upgraded and expanded to form the spearhead of a community-based pilot-scale Urban Malaria Control Programme (UMCP) in the three municipalities of Dar es Salaam: namely Ilala, Kinondoni and Temeke. This adaptation and expansion to programmatic level [54] was assisted through academic support of the City Medical Office of Health by the Ifakara Health Research and Development Centre, the Department of Zoology and Marine Biology of the University of Dar es Salaam, and a number of international collaborators. This collaborative endeavour primarily facilitated much greater access to upto-date knowledge and skills, notably from colleagues facing similar challenges in Kenya.

\section{Kenya: The rusinga island child and family programme malaria surveillance team}

Rusinga Island in Suba District is an excellent example of an isolated, underdeveloped and highly disadvantaged community in western Kenya where malaria poses a major health burden in close association with increasing poverty and environmental degradation. Rusinga is home to a growing population of approximately 14,000 people with rapidly increasing levels of irrigation, urbanization of market areas, modernization in house construction, deforestation, vegetation clearance and poorly planned infrastructure development [55], leading to abundant Anopheles larval habitats near human settlements and endemic malaria transmission [29,56-62].

Mobilization of the Rusinga community in the development of their own healthcare and public health services was initially facilitated by the Rusinga Island Child and Family Programme (RICFP) of the Christian Children's Fund (CCF)-Kenya, an international non-governmental organization. The collaboration began at a health stakeholders meeting in Suba District, Western Kenya. RICFP engaged the academic partners directly and were provided, upon request, with access to the local research facilities, personnel and training through a series of open days (Figure 1). After a presentation by the academic partners on old-fashioned larval control techniques $[13,15,21,38,63]$, RICFP/CCF invited them to train volunteers on the island. Continuous and adaptive training efforts over two years culminated in the establishment of an active malaria surveillance and control programme on the island, directly supported by the University of Nairobi, which now acts as the community's link to the international research community.
It was clear that there was an active group on Rusinga Island trying very hard to combat malaria but that their access to information and training in relation to environmental management or larviciding of malaria vectors was negligible. A good example is the commonly quoted national policy which advocates clearing of bushes for a malaria control, despite evidence that it confers no lasting protection against African anophelines [64]. Although forest clearance to expose breeding sites to sunlight can be highly effective for controlling shade-loving mosquitoes, this is very species-specific and can have the opposite effect if haphazardly applied in areas with vectors that prefer sunlit water $[65,66]$. Even the greatest advocates of environmental management at the height of its popularity concluded the following [65]:

we know of no instance where a small radius of clearing about houses or inhabited centres has done any good but many instances where it has done great harm

Given that the most important malaria vectors in Kenya, An. gambiae and Anopheles arabiensis, proliferate avidly in small sunlit water bodies [30,31], such clearing of vegetation typically increases malaria risk $[25,26,67,68]$. Indeed CCF has recently found that vegetation clearance is associated with increased malaria risk on Rusinga Island [56] so this is a classic example of a policy that needs to be actively reformed [47]. Broad issues of land ownership and governance in Kenya are clearly identified as targets for change in the national Poverty Reduction Strategy Paper (PRSP) [69] and Suba District's corresponding Consultation Report [70] but, like PRSPs of most tropical nations, environmental resource development strategies are conspicuously absent $[47,71]$.

At the outset of the collaboration, none of RICFP's 67 volunteers working with the community to address their malaria problems actually knew what aquatic stage mosquitoes looked like or where they could be found. Since then, RICFP/CCF has expanded it's collaborations to include local government and a number of national and international scientists through the University of Nairobi and an operational malaria surveillance based on community participation is active on Rusinga Island. Practical demonstrations using mosquito larvae and pupae taken from local habitats and allowed to emerge into cages allowed the community members to see for themselves (Figure 2). A special training course was introduced and completed which has enabled more than 70 community volunteers to distinguish Anopheles malaria vectors from non-vector species, to classify their larval habitats and to evaluate their productivity (Figure 3 ). Direct experience strongly suggests that community members find such active and tangible participation highly interesting and rewarding. It is envisaged that this will lead to rapid and 

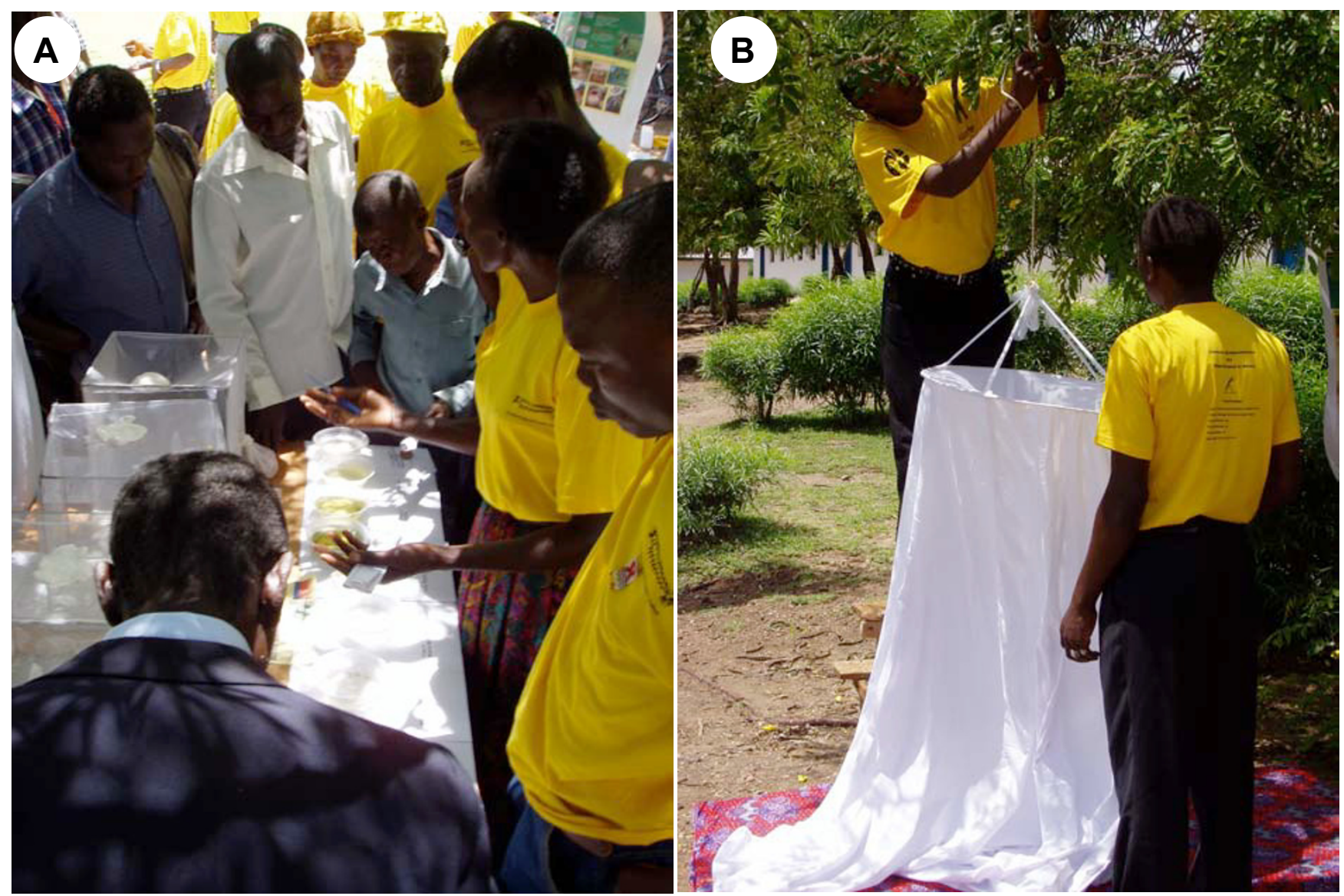

Figure 2

Community members demonstrate the life cycle of mosquitoes $(A)$ and the use of practicable adult mosquito sampling tools (B) at Rusinga Island Child and Family Programme/Christian Children's Fund-Kenya, African Malaria Day, May 2004 on Rusinga Island, Western Kenya.

sustainable changes in behaviour with knowledge transfer from children to adults and between families and friends.

The dissemination of information and adoption of appropriate malaria control activities requires all the elements of the classic theory of the Diffusion of Innovations by Everett Rogers [72]: innovation, communications channels, time and social system. The community-based larval control of malaria mosquitoes (innovation) is communicated through personal interaction during training sessions focused on learning-by-doing (communication channels). Implementation of larval control happens directly with immediate visual effects (time). Community members and health stakeholders (social system) all participate in the decision-making, planning, action and evaluation of this project that aims to enable local people to take control over their own health situation. These central elements seem to favour the process of dissemination of the innovation represented by larval surveillance and control. Additionally, this approach addresses a felt com- munity need and is not an imposed activity but rather responds to their interest and eagerness to solve their malaria problem. The information is easy to understand and apply with low financial input. There is no obvious risk involved and results are easily experienced. It is, therefore, possible to envisage a rapid dissemination of information about community-based larval malaria control activities among members of the community.

The experience on Rusinga bear a striking resemblance to those reported during the development of primary health care systems in nearby districts over two decades ago [73]. The Saradidi Rural Health Development Programme [74] demonstrated that parasitaemia and anaemia in pregnant mothers could be effectively tackled by community volunteers [75], who were prepared to contribute substantial time and effort with little remuneration [73]. These primary health care programmes are still operational today and it is notable that the academic support required to maintain them has been institutionalized in the form of 


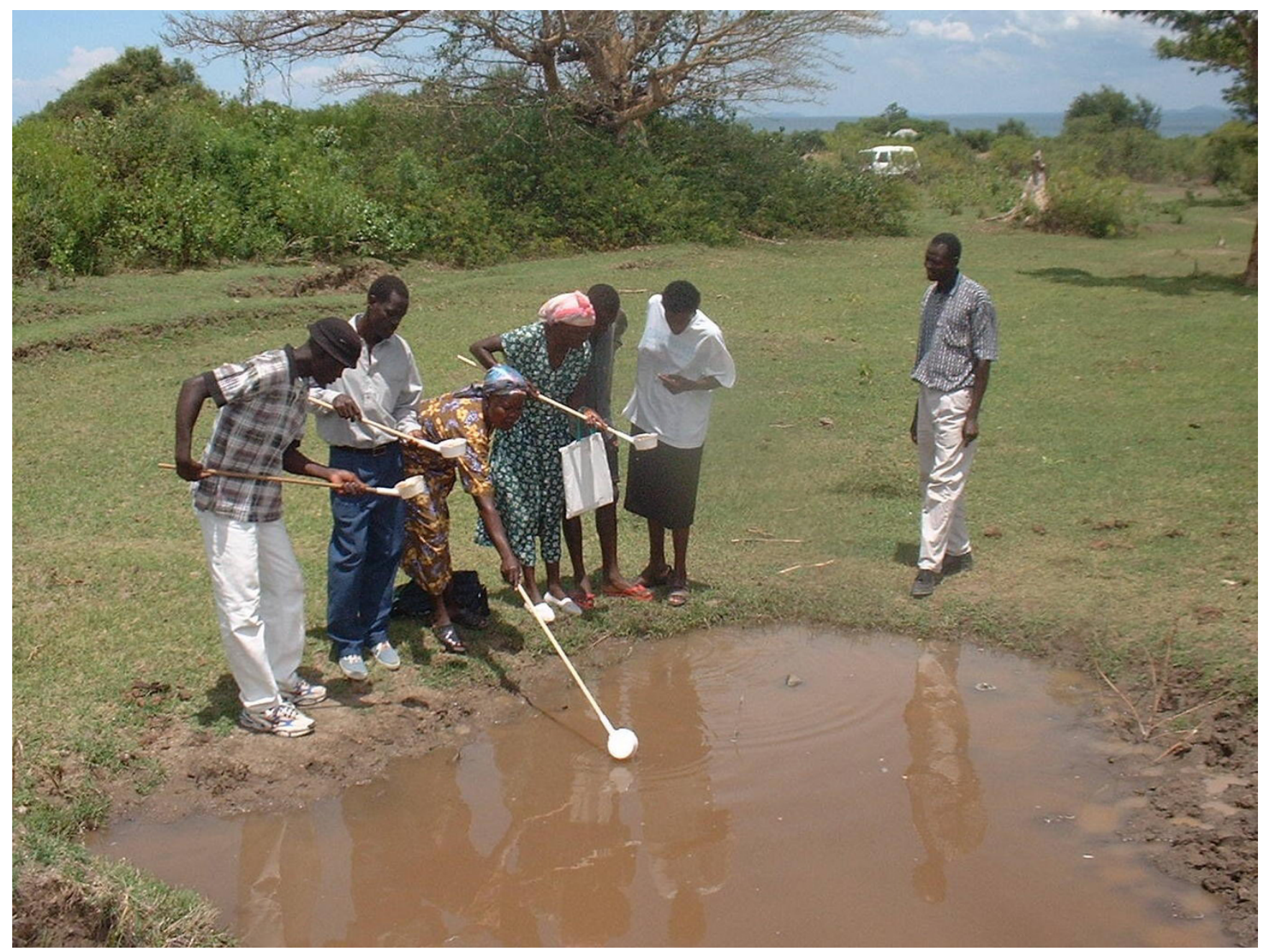

Figure 3

Field training of Rusinga Island Child and Family Programme community volunteers in sampling for mosquito larvae and pupae at Kaswanga, Rusinga Island, western Kenya.

the Teaching Institute for Community Health in Kisumu which continues to train community health workers. Although the academic side of the Rusinga Island collaboration was mainly initiated by international partners directly with the community, this is not a viable mechanism for scaling up to national levels. Therefore, responsibility for running the malaria control project has now been handed over to Kenyan scientists based at the University of Nairobi which acts as the link institute between the international partners and the community on Rusinga (Figure 4). Since then collaborative linkages have been established with a project with similar objectives but different origins in the quite different urban setting of Dar es Salaam in neighbouring Tanzania.

\section{Tanzania: The dar es salaam urban malaria control programme}

The history of malaria control in Dar es Salaam [76] dates back more than 100 years, commencing when the area was a German possession [77-79] Larval control of mosquitoes, emphasizing environmental management has played an important role in malaria control in Dar es Salaam and other Tanzanian cities for much of the $20^{\text {th }}$ century $[76,77]$. Urban malaria control in Tanzania during the 1960s relied heavily upon larviciding and community-implemented environmental management such as drainage, filling, and other engineering works $[40,77,80,81]$, resulting in malaria transmission that was considered to be of limited magnitude[40,77,80,81] In 


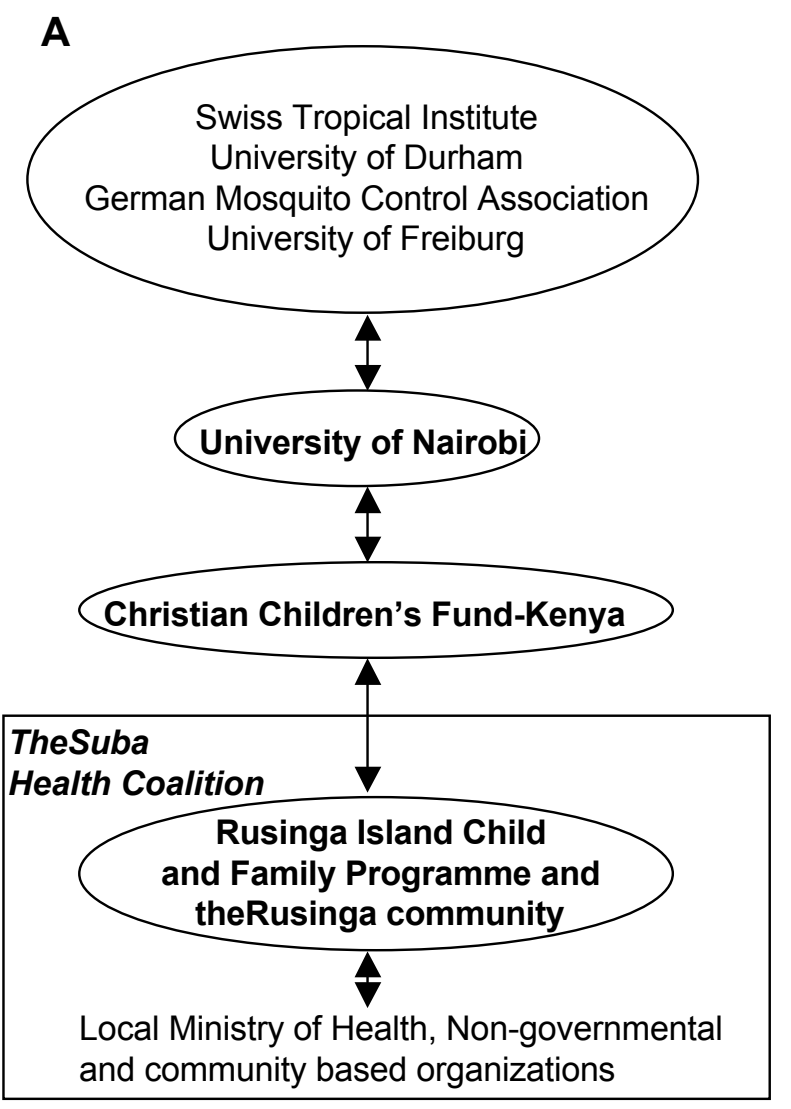

B

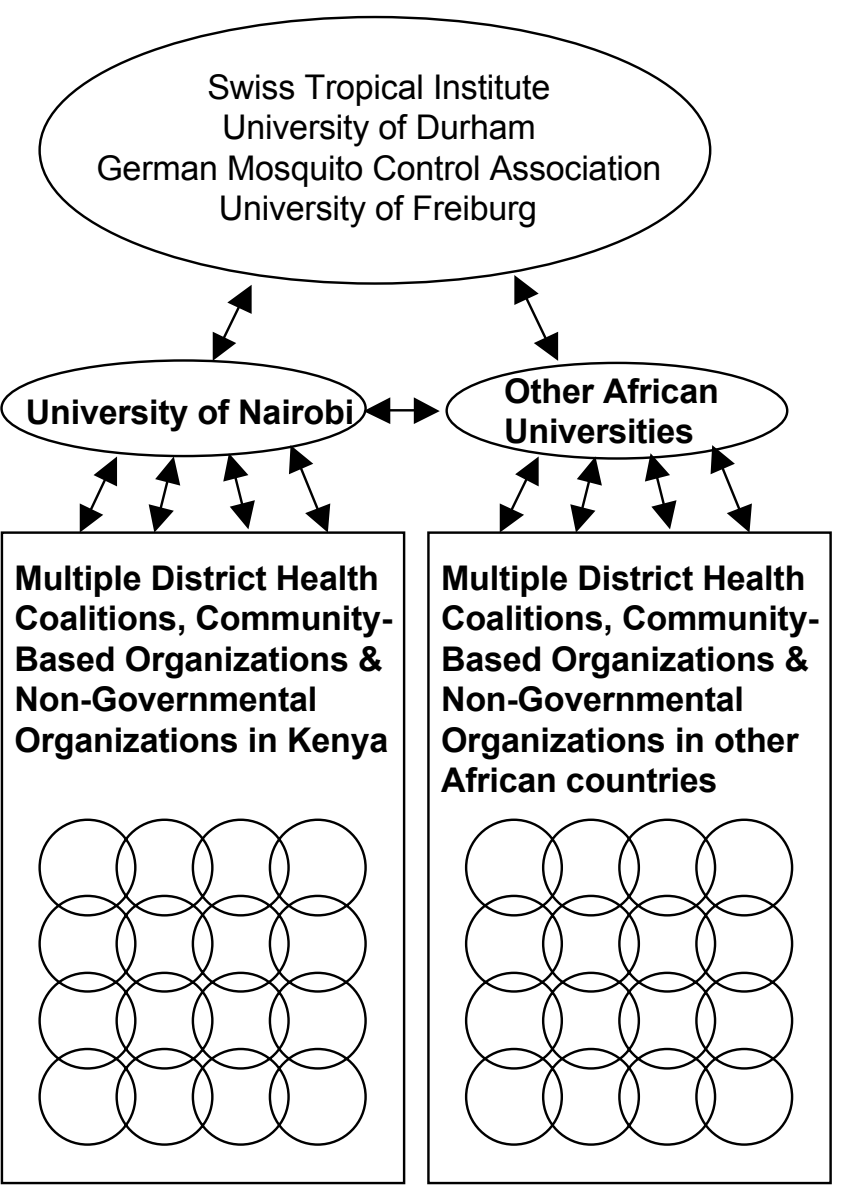

\section{Figure 4}

A diagrammatic of the planned institutional frameworks, as envisaged in June 2002, as a means to strengthen malaria control capacity in Rusinga and additional malarious communities in the short (A) and long (B) term.

1972, adverse economic conditions, combined with poor restructuring during the transition to decentralization, resulted in the deterioration of the urban health system, and chemotherapy was the only anti-malaria intervention left in place. Additionally, policy shifts at that time encouraged the citizens of Tanzania, including urban dwellers, to engage in income-generating activities, notably agriculture, which led to intensified cultivation of rice, vegetables and other crops in peri-urban areas. This increased emphasis on urban cultivation may have contributed to a ten-fold increase in the density of Anopheles in Dar es Salaam by the early 1980s [82].

In 1987, the Government of Japan, through the Japan International Cooperation Agency (JICA), provided external assistance for urban malaria control in Dar es Salaam and Tanga to reinitiate mosquito abatement in these urban centres. This programme was successful in terms of community-implemented environmental management, particularly the rehabilitation of drainage infrastructure (Figure 5) $[76,83]$ but national ownership and capacity were not sufficiently developed by this programme to achieve sustainability and the programme ended in 1996. Although valuable lessons about working with the community were learned [84], the project retained a centralized structure as a vertical programme directly under the Ministry of Health and was poorly adapted to working in a participatory fashion, even to the extent that indoor residual spray programmes had to be abandoned in favour of bednet distribution because residents refused access to their houses $[76,83]$.

In recent years, the ten-year Dar es Salaam Urban Health Project $[8,85,86]$, has considerably strengthened healthcare and public health infrastructure within the city through a decentralized health system [7], which is also 

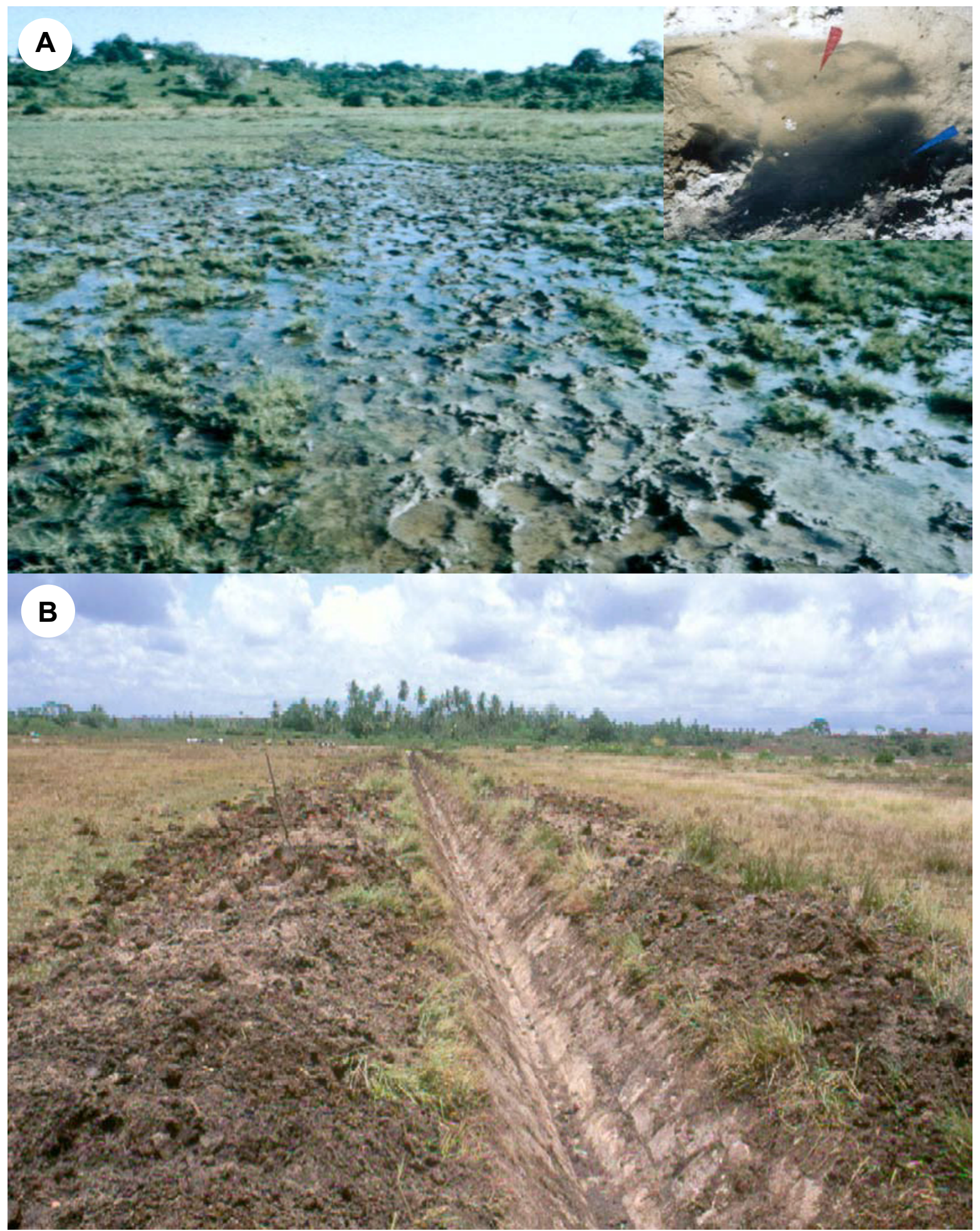

\section{Figure 5}

An example of successful, community implemented drain rehabilitation. A: Utofu salt marsh at the north-eastern end of Tanga, Tanzania. Insert is a hoof print harbouring a larva (blue arrow) and five pupae (red arrow) of Anopheles merus. Two to three boarding students were reported to die every year of high fever in Galanos High School on the hill shown on the background. 5B: One week after excavation of drains by community members assembled by the school. 


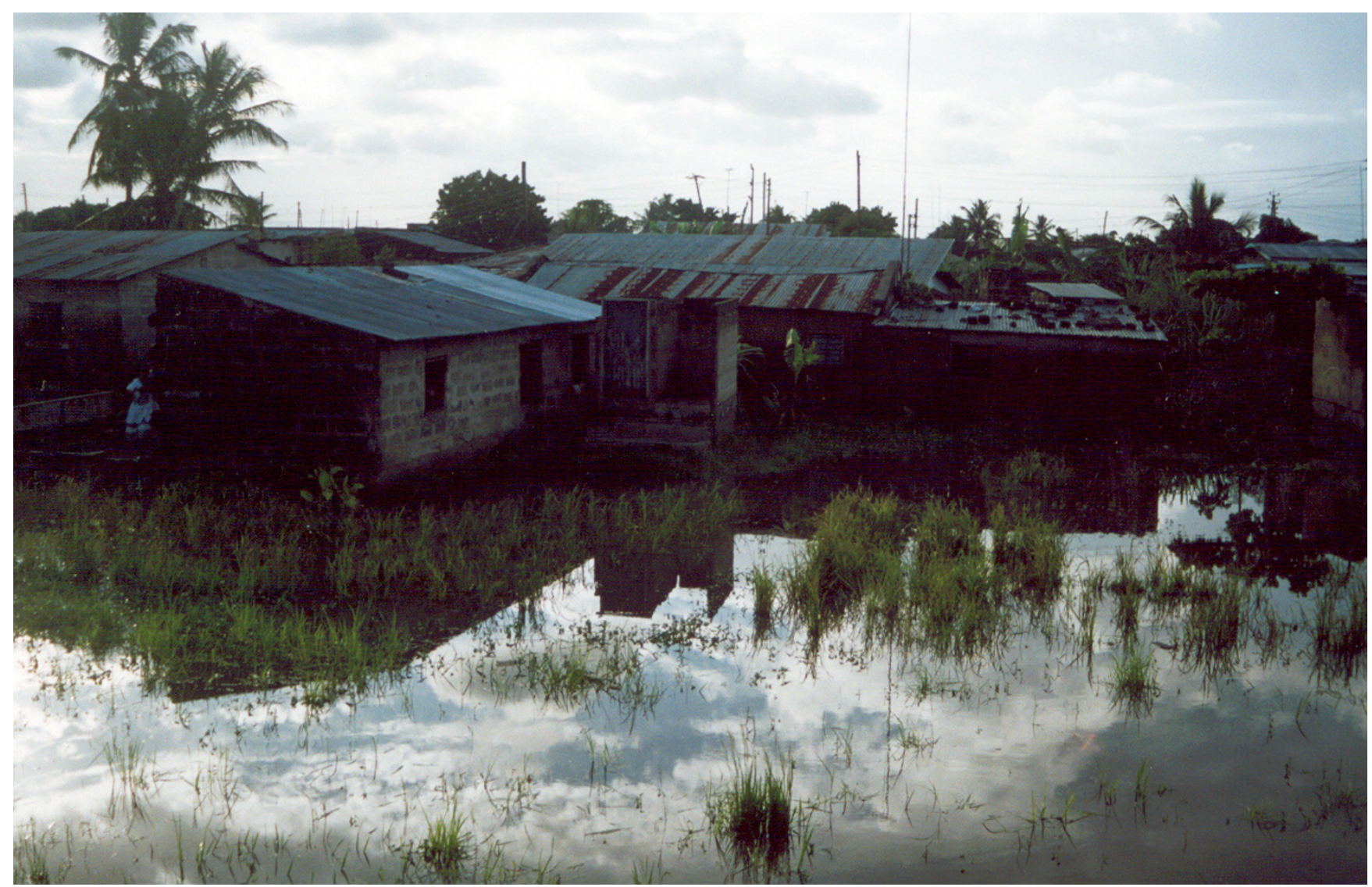

Figure 6

Examples of flooded areas in the poorly planned settlements of Vingunguti in llala municipality, Dar es Salaam, Tanzania.

ideal for delivering community-based vector control interventions $[15,34,39,87]$. This degree of autonomy enabled Ilala Municipal Council to independently conceive, fund and implement a community-based mosquito surveillance programme as an entirely local initiative in early 2002. Supplementing ongoing programmes for social marketing of ITNs and improved access to effective diagnosis and treatment [88], teams of community members were recruited to map and characterize the extensive breeding sites provided by intensive urban agriculture and poorly planned settlement (Figure 6) which abound in Dar es Salaam [76,89] and many other African cities $[19,20,90-93]$. Weekly surveys for larval and adult mosquitoes were piloted in 7 of the 22 wards of Ilala Municipality as a preliminary step towards IVM by larviciding and environmental management. Furthermore, all three municipal councils had actively promoted a variety of locality-specific community-based environmental management schemes such as trench digging and collection of solid waste refuse to prevent obstruction of such drains (Figure 7). In June 2003 the City Medical Office of Health $(\mathrm{CMOH})$ convened a stakeholders meeting for all con- cerned with malaria in Dar es Salaam, and invited a consortium of national and international scientific partners, including those involved with the Rusinga Island project in Kenya. Consensus was reached by all stakeholders that control of aquatic-stage mosquitoes, particularly source reduction through environmental management, was highly desirable and should be added to the national priority interventions to complete an integrated suite of interventions for the city. With support from the national and international academic partners, the City Medical Office then formulated a detailed implementation plan for evaluating the incremental effectiveness of larval control delivered by community members in 15 of the 73 wards of Dar es Salaam, in addition to the existing national programme interventions. Importantly, this demand-driven implementation plan for the UMCP built upon the community-based systems developed in Ilala, in which responsibility for routine mosquito surveillance is delegated to individual community members, known as Community-Owned Resource Persons (CORPs), appointed and managed through Street Health Committees. 


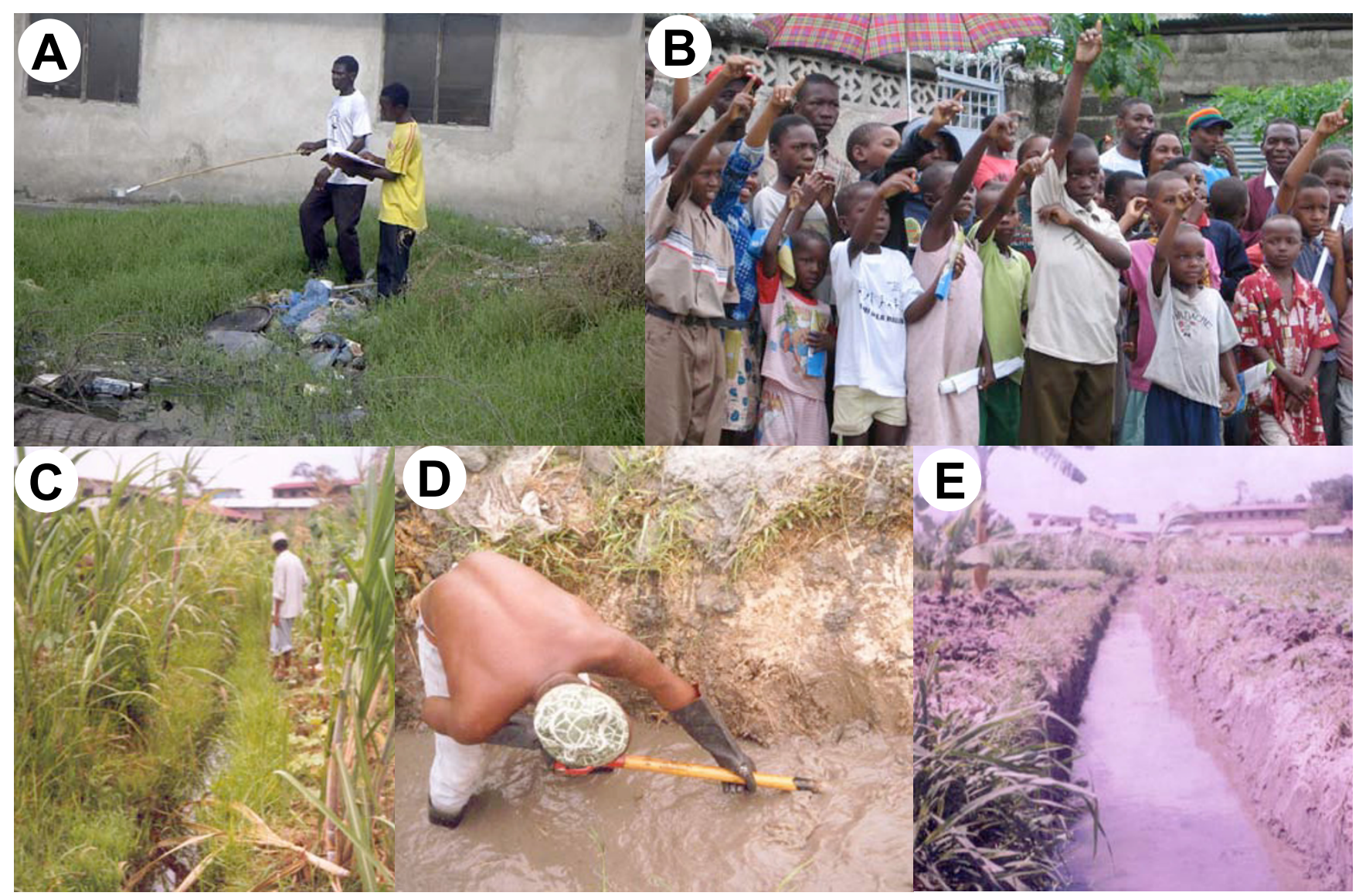

Figure 7

Examples of community-based malaria surveillance and control in Dar es Salaam. A. Community Own Resource Persons mapping and characterizing mosquito breeding sites in Vingunguti ward, llala Municipality in May 2004. B. Children participate in a quiz about malaria and mosquitoes in Mchikichini ward, llala Municipality, in April 2004. C. Extensive agricultural breeding sites associated with neglected drains adjacent to Ruihinda Primary School (background), Kigogo Ward, Kinondoni Municipality, in June 200I. D. Kinondoni Municipal Council workers rehabilitate the drain to lower the water table in August 200I. E. The same plots in September 2001 .

The consensus view of the stakeholders was that it was essential to strengthen the capacity of research and training institutions in Tanzania, within the initial pilot period of the programme, to build the necessary academic support base required to maintain the essential skills base on an indefinite basis. The primary national institutes involved included the Ifakara Health Research and Development Centre and the Department of Zoology and Marine Biology at the University of Dar es Salaam. These institutes were identified as not only supporting institutes but also as targets for strengthening training capacity so that the quantity and quality of applied ecologists available at undergraduate and graduate levels for recruitment to mosquito control programmes could be improved. Although this community-academic collaboration differs considerably from Rusinga in its setting and origins, the partnership has already begun to address capacity deficits by bringing expertise in operational mosquito control to the Municipal and City teams, including over 100 CORPs (Figure 7). As on Rusinga, the academic partners observed that standards of training and practice were initially quite poor within the existing municipal health teams who had had no expert training or access to current training material relating to mosquito abatement.

In November 2003, the Centre for Enhancement of Effective Malaria Interventions (CEEMI [94]) of the National Institute for Medical Research (NIMR) and the National Malaria Control Programme (NMCP) of Tanzania conducted a sensitization workshop with the country's Members of Parliament (MPs) aimed at soliciting for their support in promoting the use of ITNs in line with the National Medium-Term Strategic Plan [88]. While the MPs generally endorsed the interventions prioritized by the national plan, particularly the use of ITNs, many requested reconsideration of mosquito abatement, which 
many of them remembered from previous programmes, and greater support for such activities. Immediately afterward, at a meeting held in Dar es Salaam and sponsored by Tanzania NGOs' Alliance Against Malaria (TaNAAM), it became apparent that, NGOs and CBOs, including scouts and girl guides, were willing and ready to undertake many tasks pertaining to malaria control at community level but lacked the necessary skills and coordination mechanism. Thus, although the local circumstances and mode of interaction proved quite different to the Rusinga scenario, the message from the community to ecologists, health scientists and policy makers was clear: the people of Tanzania requested help from their national institutes to develop mosquito abatement programmes similar to those they have experienced in the past (See references $[76,80,95]$ for reviews).

\section{Discussion}

The Rusinga Island project has been a rewarding and enjoyable experience for all partners because the actual nature of the collaboration was determined by the community and the academic scientists were integrated into their activities rather than vice versa. Similarly, the initial reimplementation of mosquito abatement activities in urban Dar es Salaam was an entirely local initiative that was conceived, planned, implemented and funded by the Ilala Municipal Council in collaboration with community representatives right down to the level of street chairpersons and ten-cell unit leaders. As the community of Tanzania make their voices heard through grassroots community-based field workers, CBOs, NGOs and elected parliamentary representatives, academia has been challenged to increase the level of research and training support it provides to district-level vector control initiatives.

Many communities across Africa are just as active and determined as the residents of Dar es Salaam and Rusinga to implement malaria control through their own CBOs and NGOs but have had little access to the basic information and training which would enable them to do so. Unlike the parasites which actually cause malaria illness and death, the mosquitoes that carry them are readily visible, distinguishable and vulnerable to the community members upon whom they feed. Malaria-endemic Africa is home to 521 million community members [96], many of whom could be engaged to apply low technology interventions at minimum cost given the basic skills to dip for larvae, trap adult mosquitoes, distinguish Anopheles and spray non-toxic bacterial insecticides. For now, the evidence base for integrated malaria vector management is limited to a few dusty books that precede the advent of modern epidemiological tools. Direct experience with mosquito abatement in Africa is rapidly fading from living memory. Also, the implementation of larval control through community-based systems remains an unproven approach for malaria prevention in Africa. While a number of efficacy and effectiveness trials of IVM are underway across Africa, no clear consensus about how best to achieve comprehensive or targeted coverage yet exists [97]. The existing expertise of national academic institutions to support IVM, as well as the evidence base to justify it, are not yet sufficient for inclusion in national programmes. Community-based IVM should therefore only be practiced as an operational research activity until sufficient evidence and capacity is present to enable implementation at national level. Because researchers can never directly support every community in Africa, community-based IVM approaches should be incorporated into undergraduate teaching programmes in the near future so that sufficient numbers of practitioners can implement effective programmes on national scales. Mobilization of communities across Tanzania, Kenya, or any other country in Africa to implement communitybased larval control will require large numbers of competent mosquito ecologists at diploma and bachelors' level, as well as the masters and doctoral graduates who will train and direct them. In order to effectively teach community-based IVM in the future, academic ecologists need to rapidly engage in relevant operational research programmes so that knowledge of this challenging topic goes beyond reading from outdated books to include relevant, contemporary experience. The close linkage between research and control activities was a key factor in the success of the Onchocerciasis Control Programme [42], as well as malaria control programmes from the first half of the century [98]. The same integration needs to be achieved between community-based malaria control and vector ecology research in Africa. Academic ecologists engaged in entomology, engineering, agricultural, zoology or environmental sciences should be more actively supported as partners for Rolling Back Malaria.

\section{Conclusion}

It remains to be seen whether community-based IVM can be cost-effective and sustainable so it remains an operational research activity until sufficient contemporary evidence is provided. Ecologists at African academic institutions are ideally positioned to develop the evidence base and scale up capacity for community-based implementation of practical environmental and entomological malaria control skills with technologies that already exist and are readily available. They should now be supported to fulfil this neglected role.

\section{Competing interests}

Both the Rusinga and Dar es Salaam projects have been supported financially by Valent Biosciences Corporation, a commercial manufacturer of microbial larvicides. 


\section{Authors' contributions}

The views expressed in this opinion article reflect the outcome of extensive discussions amongst the authors, and with the communities they work with in Kenya and Tanzania. The manuscript was drafted by GFK in consultation with all the other authors who participated in the activities described and agree with the final submitted form.

\section{Acknowledgements}

We thank the community of Rusinga Island, especially the members and volunteers of the Rusinga Island Child and Family Programme for their insight, energy, devotion and hard work. We also thank the residents and the City Council and Municipal Councils of Dar es Salaam for their keen involvement and input in developing a plan for integrated malaria control. Prof. B. Singer provided essential academic and administrative support to both projects, without which they would not have been possible. We thank the management and staff of the International Centre of Insect Physiology and Ecology for access to facilities and services at Mbita Point Research and Training Centre and for many stimulating discussions. Activities leading to this paper were supported by the Christian Children's Fund, the Municipal Councils of Ilala, Temeke and Kinondoni, the City Council of Dar es Salaam, National Institutes of Health programmes for Health Environment and Economic Development (Award number R2 I TW-006535), International Centre for Infectious Diseases Research (Award number ICIDR-UI9AI45II) and Actions in Building Capacity (Award number ABC-D43TW0I I42), as well as Valent Biosciences Corporation, the Bill and Melinda Gates Foundation (Award number 23750), the Environmental Health Project of the United States Agency for International Development and the Swiss Tropical Institute. GFK is supported by a Wellcome Trust International Research Career Development Fellowship.

\section{References}

I. WHO/UNICEF: The African Malaria Report 2003. Geneva, WHO/UNICEF; 2003:120.

2. Kikumbih N, Hanson K, Mills A, Mponda H, Schellenberg JA: The economics of social marketing: the case of mosquito nets in Tanzania. Soc Sci Med 2005, 60:369-38I.

3. Magesa SM, Lengeler C, deSavigny D, Miller JE, Njau RJ, Kramer K, Kitua A, Mwita A: Creating an "enabling environment" for taking insecticide treated nets to national scale: the Tanzanian experience. Malar J 2005, 4:34.

4. Rowland M, Webster J, Saleh P, Chandramohan D, Freeman T, Pearcy B, Durrani N, Rab A, Mohammed N: Prevention of malaria in Afghanistan through social marketing of insecticide-treated nets: evaluation of coverage and effectiveness by cross-sectional surveys and passive surveillance. Trop Med Int Health 2002, 7:813-822

5. Mathanga DP, Campbell CH, Taylor TE, Barlow R, Wilson ML: Reduction of childhood malaria by social marketing of insecticide treated nets: A case-control study of effectiveness. American Journal of Topical Medicine and Hygiene 2005, 73:622-625.

6. Oyediran AB, Ddumba EM, Ochola SA, Lucas AO, Koporc K, Dowdle WR: A public-private partnership for malaria control: lessons from the Malarone Donation Programme. Bull World Health Organ 2002, 80:817-82I.

7. Mtasiwa D, Seigfreid G, Tanner M, Pichette P: The Dar es Salaam City/Region minimum package of health and related management activities: From managing diseases to managing health systems. Dar es Salaam, Dar es Salaam City Medical Office of Health; 2003:216.

8. Boller C, Wyss K, Mtasiwa D, Tanner M: Quality and comparison of antenatal care in public and private providers in the United Republic of Tanzania. Bull World Health Organ 2003, 81:II6-I22.

9. Government of Tanzania: Tanzania Joint Health Review. Dar es Salaam, Ministry of Health, United Republic of Tanzania; 2003:15.
10. Ghebreyesus TA, Witten KH, Getachew A, O'Neill K, Bosman A, Teklehaimanot A: Community-based malaria control in Tigray, northern Ethiopia. Parassitologia 1999, 41:367-37I.

II. Onwujekwe O, Chima R, Shu E, Nwagbo D, Akpala C, Okonkwo P: Altruistic willingness to pay in community-based sales of insecticide-treated nets exists in Nigeria. Soc Sci Med 2002, 54:519-527.

12. Killeen GF, Seyoum A, Knols BGJ: Rationalizing historical successes of malaria control in Africa in terms of mosquito resource availability management. American Journal of Topical Medicine and Hygiene 2004, 71 (Supplement 2):87-93.

13. Utzinger J, Tozan Y, Singer BH: Efficacy and cost effectiveness of environmental management for malaria control. Tropical Medicine and International Health 2001, 6:677-687.

14. Watson M: African highway: The battle for health in central Africa. London, John Murray; 1953:294

15. Killeen GF, Fillinger U, Kiche I, Gouagna LC, Knols BG]: Eradication of Anopheles gambiae from Brazil: lessons for malaria control in Africa? Lancet Infectious Diseases 2002, 2:618-627.

16. Shousha AT: Species-eradication. the eradication of Anopheles gambiae from Upper Egypt, 1942-1945. Bull WId Hlth Org 1948, 1:309-353.

17. Utzinger J, Tanner M, Kammen DM, Killeen GF, Singer BH: Integrated programme is key to malaria control. Nature 2002, 419:43I.

18. WHO: Global Strategic Framework for Integrated Vector Management. Geneva, World Health Organization; 2004:15.

19. Robert V, Maclntyre K, Keating J, Trape JF, Duchemin JB, Warren M, Beier JC: Malaria transmission in urban sub-Saharan Africa. American Journal of Tropical Medicine and Hygiene 2003, 68:169-176.

20. Keiser J, Utzinger J, Castro MC, Smith TA, Tanner M, Singer BH Urbanization in sub-Saharan Africa and implication for malaria control. American Journal of Tropical Medicine and Hygiene 2004, 7 I (Supplement 2): I | 8-127.

21. Killeen GF: Following in Soper's footsteps: northeast Brazil 63 years after eradication of Anopheles gambiae. Lancet Infectious Diseases 2003, 3:663-666.

22. Soper FL, Wilson DB: Anopheles gambiae in Brazil: 1930 to 1940. New York, The Rockefeller Foundation; 1943:262.

23. Keating J, Macintyre K, Mbogo CM, Githure JI, Beier JC: Characterization of potential larval habitats for Anopheles mosquitoes in relation to urban land-use in Malindi, Kenya. International Journal of Health Geographics 2004, 3:9.

24. Jacob BG, Regens JL, Mbogo CM, Githeko AK, Keating J, Swalm CM, Gunter JT, Githure JI, Beier JC: Occurrence and distribution of Anopheles (Diptera: Culicidae) larval habitats on land cover change sites in urban Kisumu and urban Malindi, Kenya. Journal of Medical Entomology 2003, 40:777-784.

25. Minakawa N, Sonye G, Mogi M, Yan G: Habitat characteristics of Anopheles gambiae s.s. larvae in a Kenyan highland. Medical and Veterinary Entomology 2004, 18:30I-305.

26. Minakawa N, Munga S, Atieli F, Mushinziamana E, Zhou G, Githeko AK, Yan G: Spatial distribution of Anopheline larval habitats in the western Kenyan highlands: effect of land cover types and topography. American Journal of Topical Medicine and Hygiene 2005, 73:157-165.

27. Minakawa N, Sonye G, Yan G: Relationship between occurence of Anopheles gambliae s.l. (Diptera: Culicidae) and size and stability of larval habitats. Journal of Medical Entomology 2005, 42:295-300.

28. Sattler MA, Mtasiwa D, Kiama M, Premji Z, Tanner M, Killeen GF, Lengeler $C$ : Habitat characterization and spatial distribution of Anopheles sp. mosquito larvae in Dar es Salaam (Tanzania) during an extended dry period. Malar J 2005, 4:4

29. Fillinger U, Sonye G, Killeen GF, Knols BGJ, Becker N: The practical importance of permanent and semi-permanent habitats for controlling aquatic stages of Anopheles gambiae sensu lato mosquitoes: operational observations from a rural town in Western Kenya. Tropical Medicine and International Health 2004 , 9:1274-1289.

30. Holstein MH: Biology of Anopheles gambiae. Geneva, World Health Organization; 1954: 173.

3I. Gillies MT, DeMeillon B: The Anophelinae of Africa South of the Sahara (Ethiopian zoogeographical region). Johannesburg, South African Institute for Medical Research; 1968. 
32. Becker N: Community participation in the operational use of microbial control agents in mosquito control programmes. Bulletin of the Society of Vector Ecology 1992, I 7: I I4- I I8.

33. Becker N: Microbial control of mosquitoes: Management of the upper rhine mosquito population as a model programme. Parasitology Today 1997, I 3:485-487.

34. Gubler D, Clark GG: Community-based integrated control of Aedes aegypti: a bried overview of current programmes. Amer J Trop Med Hyg 1994, 50:50-60.

35. Soper FL: The elimination of urban yellow fever from the Americas through eradication of Aedes aegypti. American Journal of Public Health 1963, 53:7-16.

36. WHO: Malaria Entomology and Vector Control: Part I: Learner's Guide, Trial Edition. 2003, WHO/CDS/CPE/SMT/ 2002. I 8 Rev. I.:69.

37. Anonymous: A handbook of urban mosquito control. , Division of Vector Control, Ministry of Health, Uganda; 1970:I30.

38. Kitron $U$, Spielman A: Suppression of transmission of malaria through source reduction: antianopheline measures applied in Israel, the United States, and Italy. Review of Infectious Diseases 1989, I I:391-406.

39. Kay BH, Nam VS, Tien VT, Yen NT, Phong TV, Diep VTB, Ninh TU, Bektas A, Aaskov JG: Control of Aedes vectors of dengue in three provinces of Vietnam by use of Mesoclops (Copepda) and community-based methods validated by entomologic, clinical, and serological surveillance. American Journal of Tropical Medicine and Hygiene 2002, 66:40-48.

40. Bang YH, Sabuni IB, Tonn RJ: Integrated control of urban mosquitoes in Dar es Salaam using community sanitation supplemented by larviciding. East African Medical Journal I975, 52:578-588.

4I. Hougard JM, Yameogo L, Seketeli A, Boatin B, Dadzie KY: Twentytwo years of blackfly control in the onchocerciasis control programme in West Africa. Parasitology Today 1997, I 3:425-43 I.

42. Remme $\mathrm{JH}$ : Research for control: the onchocerciasis experience. Trop Med Int Health 2004, 9:243-254.

43. Freeman $A R$, Lammie PJ, Houston R, LaPointe MD, Streit TG, Jooste PL, Brissau JM, Lafontant JG, Addiss DG: A community-based trial for the control of lymphatic filariasis and iodine deficiency using salt fortified with diethylcarbamazine and iodine. $\mathrm{Am} J$ Trop Med Hyg 200I, 65:865-87I.

44. Norman G, Joseph A, Theodore A, Maruthamuthu M: Communitybased teaching of tropical diseases: an experience with filariasis. Trop Doct 1999, 29:86-89.

45. Selve BP, Bwadua S, Misa M, James K, Usurup JP, Turner P, Melrose W, Yad W, Samuel R, Eddie C: Community empowerment in the control of lymphatic filariasis in Misima, Milne Bay Province using diethylcarbamazine in combination with albendazole. PN G Med J 2000, 43:183-187.

46. Catley A, Leyland T: Community participation and the delivery of veterinary services in Africa. Prev Vet Med 200I, 49:95-II3.

47. Steel P, Le-Grand S, Dobie P, Hazelwood P, Bojo J: Linking poverty reduction and environmental management. , DFID/EC/ UNDP/World Bank; 2002:44.

48. Wisner B, Blaikie $P$, Cannon T, Davis I: At risk: Natural hazards, people's vulnerability and disasters. 2nd edition. New York, Routledge; 2004:47I

49. Bos R, Birley MH, Furu P, Engel C: Health Opportunities in Development: A course manual on developing intersectoral decision-making skills in support of Health Impact Assessment. Copenhagen, Denmark, World Health Organization; 2003:280.

50. Savan B, Morgan AJ, Gore C: Volunteer environmental management and the role of Universities: The case of Citizen's environment watch. Environmental Management 2003, 3 I:56 I-568.

51. Booman M, Sharp BL, Martin CL, Manjate B, La Grange JJ, Durrheim DN: Enhancing malaria control using a computerized management system in southern Africa. Malar J 2003, 2: I3.

52. Martin C, Curtis B, Fraser C, Sharp B: The use of a GIS-based malaria information system for malaria research and control in South Africa. Health Place 2002, 8:227-236.

53. Adams WM, Hulme D: If community conservation in the answer in Africa, what is the question? Oryx 2001, 35:193-200.

54. Mtasiwa D, Kiama GM, Killeen GF: Integrated malaria control in Dar es Salaam: Programme Guidebook. Dar es Salaam, Tanzania, Dar es Salaam City Council; 2004:|4I.
55. Connelly TW: Population Pressure, Labor Availability, and Agricultural Disintensification: The Decline of Farming on Rusinga Island, Kenya. Human Ecology 1994, 22:2-9.

56. Kantai O, Mugo M, Kerkering TM: Contribution of malaria to under five mortality in an area of Western Kenya (A contribution to "Fresh Air: A Malaria Technical Update"). $200 \mathrm{I}$.

57. Shililu J, Mbogo CMN, Mutero C, Gunter J, Swalm C, Regens JL, Keating J, Yan G, Githure Jl, Beier JC: Spatial distribution of Anopheles gambiae, Anopheles funestus and malaria transmission in Suba district, Western Kenya. Insect Science and Applications 2003, 23:187-196.

58. Minakawa N, Githure Jl, Beier JC, Yan G: Anopheline mosquito survival strategies during the dry period in western Kenya. Journal of Medical Entomology 2001, 38:388-392.

59. Minakawa N, Mutero CM, Githure JI, Beier JC, Yan G: Spatial distribution and habitat characterization of Anopheline mosquito larvae in Western Kenya. American Journal of Tropical Medicine and Hygiene 1999, 61:1010-1016.

60. Minakawa N, Seda P, Yan G: Influence of host and larval habitat distribution on the abundance of African malaria vectors in Western Kenya. American Journal of Tropical Medicine and Hygiene 2002, 67:32-38

6I. Mutero CM, Ouma J, Agak BK, Wanderi JA, Copeland RS: Malaria prevalence and use of self-protection measures against mosquitoes in Suba district. East African Medical Journal 1998 , 75: II-16.

62. Bousema JT, Gouagna LC, Meutstege AM, Okech BE, Akim NI, Githure Jl, Beier JC, Sauerwein RW: Treatment failure of pyrimethamine-sulphadoxine and induction of Plasmodium falciparum gametocytaemia in children in western Kenya. Trop Med Int Health 2003, 8:427-430.

63. Utzinger J, Tozan Y, Doumani F, Singer BH: The economic payoffs of integrated malaria control in the Zambian copperbelt between 1930 and 1950. Tropical Medicine and International Health 2002, 7:657-677.

64. Ribbands CR: Effects of bush clearance on flighting of West African Anophelines. Bulletin of Entomological Research 1946, 37:33-4I.

65. Hackett LW, Russell PF, Scharff JW, Senior White R: The present use of naturalistic measures in the control of malaria. Bulletin of the Health Organisation of the League of Nations 1938, 7:1046-1064.

66. Takken W, Snellen WB, Verhave JP, Knols BG], Atmosoedjono S: Environmental measures for malaria control in IndonesiaAn historical review on species sanitation. In Wageningen Agricultural University Papers Volume 90-7. Wageningen, Agricultural University Wageningen; 1990:167.

67. Briet OJ, Dossou-Yovo J, Akodo E, van de Giesen N, Teuscher TM: The relationship between Anopheles gambiae density and rice cultivation in the savannah zone and forest zone of Cote d'Ivoire. Trop Med Int Health 2003, 8:439-448.

68. Linblade KA, Walker ED, Onapa A, Katungu J, Wilson ML: Land use change alters malaria transmission parameters by modifying temperature in a highland area of Uganda. Tropical Medicine and International Health 2000, 5:263-274.

69. GoK: Poverty Reduction Strategy Paper for the period 200I2004. Nairobi, Kenya, Government of the Republic of Kenya, Ministry of Finance and Planning; 2001:309.

70. Government of Kenya: Suba District PRSP: Consultation Report for the period 200I-2004. Nairobi, Kenya, Government of the Republic of Kenya, Ministry of Finance and Planning; 2001:23.

7I. Bojo J, Reddy RC: Poverty Reduction Strategies: A review of 38 interim and full PRSPs. Washington, D.C., USA, Economic and Social Development Unit, Africa Region, World Bank; 2001.

72. Rogers EM: Diffusion of innovations. 4th edition. New York, Free Press; 1995.

73. Kasaje DCO, Spencer HC, Sempebwa EKN: Characteristics and functions of community health workers in Saradidi, Kenya. Ann Trop Med Parasitol 1987, 8 I (Supplement I):56-66.

74. Kasaje DCO, Spencer HC: The Saradid, Kenya, Rural Health Development Programme. Ann Trop Med Parasitol 1987, 8I (Supplement I): I-I2.

75. Spencer HC, Kasaje DCO, Sempebwa EKN, Huong AY, Roberts JM: Malaria chemoprophylaxis to pregnant women provided by community health workers in Saradidi, Kenya. Annals of Tropical Medicine and Parasitology 1987, 8 I (Supplement I):83-89. 
76. Castro MC, Yamagata Y, Mtasiwa D, Tanner M, Utzinger J, Keiser J, Singer BH: Integrated urban malaria control: a case study in Dar es Salaam, Tanzania. American Journal of Tropical Medicine and Hygiene 2004, 7 I (Supplement 2): 103-I I7.

77. Kilama WL: Control of arthropods of public health importance. In Health and Disease in Tanzania Edited by: Mwaluko GMP, Kilama WL, Mandara PM, Murru M and MacPherson CNL. London, Harper Collins Academic; 1991.

78. Clyde DF: Malaria control in Tanganyika under the German administration-Part I. East African Medical Journal I96I, 38:27-42.

79. Clyde DF: Malaria control in Tanganyika under the German administration-Part 2. East African Medical Journal I961, 38:69-82.

80. Kilama WL: Malaria in Tanzania: past and present. In Proceedings of the IIth Annual Joint Scientific Conference with a Seminar on Malaria Control Research Arusha, Tanzania, National Institute for Medical Research; 1994.

81. Bang YH, Mrope FM, Sabuni IB: Changes in mosquito populations associated with urbanization in Tanzania. East African Medical Journal 1977, 54:403-4II.

82. Kilama WL: Malaria. In Health and Disease in Tanzania Edited by: Mwaluko GMP, Kilama WL, Mandara PM, Murru M and MacPherson CNL. London, Harper Collins Academic; 1991:1 17-132.

83. Yamagata Y: Review of Tanzania-Japan Urban Malaria Control Project (UMCP) in Dar es Salaam and Tanga (1988-1996). Dar es Salaam, Tanzania, Japan International Cooperation Agency; 1996:46.

84. Stephens C, Masamu ET, Kiama MG, Keto AJ, Kinenekejo M, Ichimori $\mathrm{K}$, Lines J: Knowledge of mosquitos in relation to public and domestic control activities in the cities of Dar es Salaam and Tanga. Bull World Health Organ 1995, 73:97-104.

85. Lorenz N, Kilima PM, Tanner M, Garner P: The right objectives in health care planning. World Health Forum 1995, 16:280-282.

86. Wyss K, Whiting D, Kilima P, McLarty DG, Mtasiwa D, Tanner M, Lorenz N: Utilisation of government and private health services in Dar es Salaam. East Afr Med J 1996, 73:357-363.

87. Lines J, Harpham T, Leake C, Schofield C: Trends, priorities and policy directions in the control of vector-borne diseases in urban environments. Health Policy and Planning 1994, 9: I I3-I 29.

88. Ministry of Health: National malaria medium term strategic plan, 2002-2007. Dar es Salaam, Ministry of Health, United Republic of Tanzania \& World Health Organization; 2002:55.

89. Dongas S: Urban vegetable production in Dar es Salaam, Tanzania: GIS-supported analysis of spatial changes from 1992 to 1999. Applied Physiogeography of the Tropics and Subtropics Reports 2001, I2:100-144.

90. Afrane YA, Klinkenberg E, Drechsel P, Owusu-Daaku K, Garms R, Kruppa $T$ : Does irrigated urban agriculture influence the transmission of malaria in the city of Kumasi, Ghana? Acta Trop 2004, 89: 125-134.

91. Staedke SG, Nottingham EW, Cox J, Kamya MR, Rosenthal PJ, Dorsey G: Short report: proximity to mosquito breeding sites as a risk factor for clinical malaria episodes in an urban cohort of Ugandan children. Am J Trop Med Hyg 2003, 69:244-246.

92. Wang SJ, Lengeler C, Smith TA, Vounatsou P, Cisse G, Diallo DA, Akogbeto M, Mtasiwa D, Teklehaimanot A, Tanner M: Rapid Urban Malaria Appraisal (RUMA) in sub-Saharan Africa. Malar J 2005, 4:40.

93. Wang SJ, Lengeler C, Smith TA, Vounatsou P, Diadie DA, Pritroipa X, Convelbo N, Kientga N, Tanner M: Rapid Urban Malaria Appraisal (RUMA) I: Epidemiology of urban malaria in Ouagadougou. Malar J 2005, 4:43.

94. ljumba J, Kitua AY: Enhancing the application of effective malaria interventions in Africa through training. American Journal of Tropical Medicine and Hygiene 2004, 71 (Supplement 2):253-258.

95. Clyde DF: Malaria in Tanzania. London, Oxford University Press; 1967:167.

96. Snow RW, Guerra CA, Noor AM, Myint HY, Hay SI: The global distribution of clinical episodes of Plasmodium falciparum malaria. Nature 2005, 434:2/4-217.

97. Killeen GF, Mukabana WR, Kalongolela MS, Kannady K, Lindsay SW, Tanner M, Caldas de Castro M, Fillinger U: Habitat targetting for controlling aquatic stages of malaria vectors in Africa. American Journal of Tropical Medicine and Hygiene 2006, In Press:.

98. Alilio MS, Bygbjerg IB, Breman JG: Are multilateral malaria research and control programs the most successful? Lessons from the past $\mathbf{1 0 0}$ years in Africa. American Journal of Tropical Medicine and Hygiene 2004, 7 I (Supplement 2):268-278.

\section{Publish with Bio Med Central and every scientist can read your work free of charge}

"BioMed Central will be the most significant development for disseminating the results of biomedical research in our lifetime. "

Sir Paul Nurse, Cancer Research UK

Your research papers will be:

- available free of charge to the entire biomedical community

- peer reviewed and published immediately upon acceptance

- cited in PubMed and archived on PubMed Central

- yours - you keep the copyright

Submit your manuscript here:

http://www.biomedcentral.com/info/publishing_adv.asp
BioMedcentral 